\title{
CHEMICAL DEGRADATION OF POLYMERS AND ADDITIVES IN ALKALINE SOLUTION: INFLUENCE OF TEMPERATURE
}

\author{
HELA BEN ZEINEB ${ }^{1,2}$, CLAUDE LE MILBEAU ${ }^{1}$, PHILIPPE \\ BLANC $^{2}$, PATRICK OLLIVIER ${ }^{2}$, LAURENT ANDRE ${ }^{1,2}$ AND \\ MOHAMMED BOUSSAFIR ${ }^{1,3}$ \\ ${ }^{1}$ ISTO \\ ${ }^{2} \mathrm{BRGM}$ \\ ${ }^{3} \mathrm{GeHCO}$ \\ Presenting Author: hela.ben-zeineb@etu.univ-orleans.fr
}

In the context of radioactive waste management, organic wastes will come into contact with alkaline cement porewaters. Such interactions could result in the release of new hydrophilic organic products [1], able to produce stable complexes with radionuclides and toxics and facilitating their migration in the surrounding environment. Among these organic wastes, the chemical degradation of polymers under alkaline conditions is still poorly documented. The present work reports results from degradation experiments, conducted on both polyvinyl chloride (PVC) and polyethylene (PE). Experiments are conducted at various temperatures (from 22 to $90{ }^{\circ} \mathrm{C}$ ) since the latter can increase the rate of reactions and the release of degradation products.

Three industrial samples of hard PVC and one sample of PE are put into contact with leaching solutions of pure water and $\mathrm{NaOH} 0.1 \mathrm{M}(\mathrm{pH}=13$; alkaline solution), for 2 temperatures $\left(22^{\circ} \mathrm{C}\right.$ and $\left.90^{\circ} \mathrm{C}\right)$, under aerobic and anaerobic $\left(\mathrm{N}_{2}\right)$ conditions. In the initial PVC samples, we detected the presence of C14-C40 alkane chains, specific from hard PVC and used as lubricant in the production process. At $22^{\circ} \mathrm{C}$, after one year, both the evolution of the dissolved organic fraction in pure water and alkaline solution in contact with PE and PVCs and the gas production are very limited. On the other hand, at $90^{\circ} \mathrm{C}$, for $\mathrm{PE}$ and one PVC sample, concentrations in organic carbon display a gradual increase over time, consistently with the evolution of the gas concentrations. A kinetic rate could be retrieved from the experiment analyses, which essentially represents the gradual release of the additives from the main solid fraction. In a further step, those results will be compared with similar experiments performed under $\gamma$-radiation in order to assess radiation influence over the organic ligand release rates.

[1] L. Van Loon, M. Glaus (1997). Journal of Polymers and the Environment 5, 97-109. 